\title{
PERCEPÇÕES DE GESTANTES SOBRE O ENVOLVIMENTO PATERNO DURANTE O PARTO E NASCIMENTO
}

\section{PERCEPTIONS OF PREGNANT WOMEN ABOUT PARENTAL INVOLVEMENT DURING CHILDBIRTH AND BIRTH}

\section{Guilherme Frederico Abdul Nour ${ }^{1} *$ Ana Jessyca Campos Sousa ${ }^{2} *$ Conceição de Maria Farias Sousa $^{3}$ Regina Claudia Correia Benício ${ }^{4}$ * Cibelly Aliny Siqueira Lima Freitas ${ }^{5}$ * Andréa Carvalho Araújo Moreira $^{6} *$ Ana Kelve de Castro Damasceno ${ }^{7}$ Maria Adelane Monteiro da Silva ${ }^{8}$}

\section{RESUMO}

Objetivo: Conhecer a percepção das gestantes sobre o acompanhamento do parceiro durante o processo parturitivo. Métodos: Estudo descritivo e exploratório com abordagem qualitativa, realizada entre os meses de fevereiro a maio de 2018, com 14 mulheres que frequentavam grupos de gestantes em um Centro de Saúde da Família no nordeste do Brasil. Os dados foram coletados mediante a técnica de grupos focais, transcritos na íntegra e analisados através de análise temática. Resultados: As percepções das mulheres expressaram-se nas seguintes categorias temáticas: Percepção da gestante sobre o envolvimento paterno e Expectativas do apoio paterno no parto e nascimento. Considerações finais: Todas as mulheres consideraram positivo esse envolvimento por acreditar que essa presença confere mais apoio, conforto, segurança, cumplicidade e parceria para ambos. Faz-se necessário, por parte dos profissionais de saúde, repensar sobre a preparação e o envolvimento do companheiro da gestante durante todo o processo de gestação, parto e nascimento.

Palavras-chave: Paternidade; Gestantes; Trabalho de arto; Parto; Enfermagem Obstétrica.

\begin{abstract}
Objective: To know the perception of pregnant women about monitoring their partner during the birth process. Methods: Descriptive and exploratory study with a qualitative approach, carried out between February and May 2018, with 14 women who attended groups of pregnant women in a Family Health Center in northeastern Brazil. Data were collected using the technique of focus groups, transcribed in full and analyzed through thematic analysis. Results: The women's perceptions were expressed in the following thematic categories: Pregnant woman's perception about paternal involvement and Expectations of paternal support in labor and birth. Final considerations: All women considered this involvement positive, believing that this presence provides more support, comfort, security, complicity and partnership for both. It is necessary, on the part of health professionals, to rethink the preparation and involvement of the pregnant woman's partner throughout the process of pregnancy, delivery and birth
\end{abstract}

Keywords: Paternity; Pregnant Women; Labor, Obstetric; Parturition; Obstetric Nursing.

\footnotetext{
${ }^{1}$ Enfermeiro Obstétrico. Mestre em Saúde da Família pela Universidade Federal do Ceará - UFC. Maternidade Escola Assis Chateaubriand. Fortaleza (CE) - Brasil. Orcid: https://orcid.org/0000-0002-5000-6203

${ }^{2}$ Enfermeira. Mestranda em Saúde da Família pela Universidade Federal do Ceará - UFC. Fortaleza (CE) - Brasil. Orcid: https://orcid.org/0000-0001-6892-147X

${ }^{3}$ Enfermeira. Mestranda em Saúde da Família pela Universidade Federal do Ceará - UFC. Fortaleza (CE) - Brasil. Orcid: https://orcid.org/0000-0002-6244-8041

${ }^{4}$ Enfermeira Obstétrica. Mestre pela Universidade de Fortaleza - UNIFOR. Maternidade Escola Assis Chateaubriand. Fortaleza (CE)

- Brasil. Orcid: https://orcid.org/0000-0003-0706-9177

${ }^{5}$ Enfermeira. Doutora em Enfermagem pela Universidade Federal do Ceará - UFC. Docente da Universidade Estadual Vale do Acaraú - UVA. Sobral (CE) - Brasil. Orcid: https://orcid.org/0000-0002-0585-5345

${ }^{6}$ Enfermeira. Doutora em Enfermagem pela Universidade Federal do Ceará - UFC. Docente da Universidade Estadual Vale do Acaraú - UVA. Sobral (CE) - Brasil. Orcid: https://orcid.org/0000-0001-9855-1449

${ }^{7}$ Enfermeira. Doutora em Enfermagem pela Universidade Federal do Ceará. Docente da Universidade Federal do Ceará - UFC. Fortaleza (CE) - Brasil. Orcid: https://orcid.org/0000-0003-4690-9327

${ }^{8}$ Enfermeira. Doutora em Enfermagem pela Universidade Federal do Ceará - UFC. Docente da Universidade Estadual Vale do Acaraú - UVA. Sobral (CE) - Brasil. Orcid: https://orcid.org/0000-0001-7579-2645
} 


\section{INTRODUÇÃO}

$\mathrm{Na}$ atualidade, estudos têm demonstrado os benefícios do envolvimento paterno em eventos que compreendem o ciclo gravídico e puerperal. Historicamente a figura masculina pouco ou quase nunca se tem envolvido no cenário parturitivo, efeito fruto do modelo assistencial tradicional e de uma cultura estritamente machista, em que a mulher é considerada como a única responsável pela gestação, parturição e criação dos filhos $^{(1-3)}$.

$\mathrm{Na}$ última década, diversas políticas foram implantadas com o intuito de qualificar a assistência ao parto e nascimento, para que as mulheres possam vivenciar esse momento de forma mais digna, respeitosa $e$ humanizada ${ }^{(4-6)}$ Uma das estratégias consideradas positivas é a promoção da presença do pai durante esses eventos. A Organização Mundial de Saúde (OMS) considera urgente o resgate e a inclusão da figura masculina durante a gestação, o nascimento e desenvolvimento de seus filhos $^{(7-8)}$.

Apesar de se tratar de um evento próprio do corpo da mulher, o homem como pai, também precisa participar em conjunto com as decisões tomadas e assumir suas responsabilidades paternas. Estudos revelam que a presença do pai como acompanhante pode contribuir positivamente no processo do parto e nascimento. O genitor é um ator importante, haja vista que a ligação emocional entre ele e o filho é determinante na sua transição para a paternidade ${ }^{(1,3,9)}$. Essa interação deve ocorrer de forma natural e estimulada pelos profissionais de saúde.

Dessa forma, o envolvimento paterno no processo inerente ao ciclo gravídico e puerperal pode ser encorajado e incentivado pelos profissionais nas mais diversas instituições de saúde, pois tende a promover envolvimento afetivo com o bebê, proporciona maior bem-estar físico e emocional para a mulher, a sensação de ser acolhida, amparada e mais segura durante o processo parturitivo. Estudos revelam também benefícios na evolução do trabalho de parto e parto, pois quando os pais transmitem segurança para mulher, pode-se reduzir as complicações na gestação, no parto e no puerpério $^{(1,9-10)}$.

Vale destacar que a presença do pai na hora do parto só deve ocorrer após uma decisão refletida e discutida pelo casal, para que a presença do mesmo não se torne uma ação forçada para ambos.

Assim, diante desse cenário, o presente estudo teve como objetivo conhecer a percepção das gestantes sobre o acompanhamento do parceiro durante o processo parturitivo.

\section{MÉTODOS}

Trata-se de um estudo exploratório com abordagem qualitativa, recorte de uma 
dissertação de mestrado da Universidade Federal do Ceará, Brasil.

$\mathrm{O}$ estudo exploratório tem como principal finalidade desenvolver, esclarecer e modificar conceitos e ideias, proporcionando uma nova visão do problema, recolocando-o sobre outro prisma. Serve também como forma de determinar um objeto de estudo, com a seleção e observação de variáveis capazes de influenciá-los ${ }^{(11)}$.

A pesquisa ocorreu na cidade de Sobral - CE, que é a principal cidade do noroeste do estado do Ceará e a segunda mais importante do estado em termos econômicos e culturais, sendo a terceira maior região metropolitana. É referência para 55 municípios, possui uma população de 208.935 habitantes. O município mantém 36 Centros de Saúde da Família e 63 equipes de Saúde da Família.

O estudo foi realizado em uma Unidade Básica de Saúde (UBS), entre os meses de fevereiro a maio de 2018. A UBS em questão é composta por quatro equipes, sendo quatro enfermeiros, três médicos e 24 Agentes Comunitários de Saúde (ACS). Essa unidade foi selecionada intencionalmente, pois constitui-se campo de atuação da extensão do grupo de pesquisa a qual os autores fazem parte e por ter um grupo de gestantes com encontros fixos.

A pesquisa foi realizada com 14 mulheres que frequentavam o grupo de gestantes quinzenalmente na referida UBS.
Estabeleceu-se como critério de inclusão, mulheres grávidas que participavam do grupo de gestantes no Centro de Saúde da Família, maiores de 18 anos e estarem em acompanhamento no referido serviço de saúde, não havendo um número exato prédefinido de participantes.

Para preservar o anonimato das participantes, estas estão identificadas na pesquisa pelo termo "participante", seguido do numeral arábico, na sequência de sua inserção na pesquisa.

Utilizou-se como método de coleta de dados o grupo focal, com a realização de duas sessões.

Grupos focais é uma técnica de pesquisa qualitativa, derivada das entrevistas grupais, que coleta informações por meio das interações grupais. $\mathrm{O}$ grupo focal é uma forma de entrevistas com grupos, baseada na comunicação e na interação. Seu principal objetivo é reunir informações detalhadas sobre um tópico específico (sugerido por um pesquisador ou moderador do grupo) a partir de um grupo de participantes selecionados ${ }^{(12)}$. Busca colher informações que possam proporcionar a compreensão de percepções, crenças, atitudes sobre um tema, produto ou serviços.

Foram duas sessões de grupos focais. Cada mulher gestante participou de uma das sessões com duração média de 02 horas. Para fazer parte da pesquisa, as participantes receberam previamente uma carta convite. 
O número de participante recomendado para o grupo focal, segundo a literatura deve variar entre seis a doze sujeitos por sessões, ter duração máxima de duas horas, com um período de aquecimento antes de iniciar as discussões e reflexões e a preservação de um tempo para encerramento do encontro ${ }^{(12)}$. Assim, optou-se por seguir essas recomendações.

A coleta de dados ocorreu no próprio serviço de saúde, no dia pactuado para ocorrer $\mathrm{o}$ encontro com as gestantes. Utilizou-se o guia norteador para subsidiar o momento, com a seguinte questão central: Qual a sua percepção em relação ao envolvimento do seu companheiro no momento do trabalho de parto, parto e nascimento.

Junto ao moderador, duas apoiadoras da pesquisa participaram dos encontros, as quais ficaram responsáveis pelos convites, organização, registros das falas e o acompanhamento do momento.

A coleta foi realizada pelo pesquisador com o auxílio de um moderador. As falas foram gravadas com auxílio de dois gravadores mediante a autorização das participantes, transcritas na íntegra para posterior análise qualitativa dos dados.

Os dados foram explorados por meio da análise de conteúdo de Bardin. Consiste no conjunto de técnicas de análise de comunicações que utiliza procedimentos sistemáticos e objetivos de descrição do conteúdo das mensagens, com a intenção da inferência lógica de conhecimentos, recorrendo a indicadores quantitativos ou não. O método de Bardin trabalha com três polos cronológicos: 1) pré-análise; 2) exploração do material; 3) tratamento dos resultados, inferência e interpretação. Neste último polo, a categorização surge como uma operação de qualificação de elementos constitutivos do conjunto. A categorização tem como primeiro objetivo fornecer, por condensação, uma representação simplificada dos dados brutos (13).

A pesquisa assegurou a ética e a dignidade em toda a sua elaboração, com respeito a Resolução 510/2016 do Conselho Nacional de Saúde, que estabelece normativas para pesquisas com seres humanos. Todas formalizaram seu aceite, após apresentação dos objetivos da pesquisa e assinaram o Termo de Consentimento Livre e Esclarecido (TCLE).

O estudo foi submetido à Comissão Científica do município e posteriormente ao Comitê de Ética em Pesquisa ${ }^{(14)}$, no qual foi aprovado sob o parecer $\mathrm{N}^{\circ} 2.454 .504$ e CAAE: 79137417.8.0000.5053.

\section{RESULTADOS}

Participaram dos grupos focais 14 gestantes, em sua maioria primigestas, que já frequentavam os encontros quinzenalmente. A princípio as mulheres demonstraram-se tímidas e retraídas, com dificuldades de 
expressar suas concepções. Optou-se então em iniciar as sessões com dinâmicas e oficinas no intuito de promover $\mathrm{O}$ envolvimento das gestantes entre si e com o moderador.

Através das atividades desenvolvidas, aos poucos as mulheres começaram a expressar suas opiniões e perspectivas acerca dos questionamentos propostos. Algumas participaram mais ativamente das discussões e outras de forma mais discreta, porém todas conseguiram se envolver durante os momentos.

O primeiro grupo focal contou com oito participantes, cinco moravam com companheiro e três eram solteiras. A idade variou entre 18 a 34 anos, com uma média de 22 anos. Quanto à ocupação, todas estavam desempregadas. Com relação à escolaridade, cinco tinham ensino fundamental incompleto e três haviam cursado o ensino médio. Das oito gestantes, quatro estavam no $3^{\circ}$ trimestre da gravidez, três no $2^{\circ}$ trimestre e uma no $1^{\circ}$. Cinco relataram ser a primeira gestação e três já tinham outros filhos. Todas nutriam expectativas de ter um parto normal na gestação atual.

$\mathrm{Na}$ segunda sessão grupal, participaram seis gestantes, três moravam com o companheiro e três eram solteiras. A idade variou entre 18 a 29 anos, a média foi 20 anos. Todas estavam desempregadas. Quatro tinham ensino fundamental e duas o ensino médio. Das seis gestantes, duas estavam no $3^{\circ}$ trimestre da gravidez e quatro no $2^{\circ}$ trimestre. Três gestantes estavam grávidas pela primeira vez e as outras três já tinham filhos. Todas também nutriam expectativas de ter um parto normal nessa gestação. Ou seja, das 14 participantes dos dois grupos focais, todas relataram ter expectativas de um parto normal.

De acordo com as observações, os encontros realizados nos grupos focais foram satisfatórios e atenderam às recomendações para a sua realização como escolha de um ambiente adequado e organizado, duração em tempo conveniente e não exaustivo, uso de roteiros para discussão entre os participantes, atuação do moderador e discussão agradável e participativa entre os sujeitos.

A partir da análise qualitativa dos relatos das sessões grupais, foram definidas duas categorias temáticas, conforme orienta Bardin, para expressar suas percepções com relação ao envolvimento paterno no processo parturitivo, as quais foram: Percepção da gestante sobre o envolvimento paterno $\mathrm{e}$ Expectativas do apoio paterno no parto e nascimento.

\section{Percepção da gestante sobre o envolvimento paterno}

O envolvimento paterno no processo parturitivo foi relado por todas gestantes como algo positivo e desejável, como pode-se evidenciar nas falas abaixo: 
Eu acho que ter a participação do companheiro é muito bom (Participante 7).

Acho importante ele ficar também, para ajudar (Participante 9).

Eu gostaria que теи еsposo pudesse ficar comigo no meu parto, vou pedir pra ele ficar, a gente é muito unido em tudo (Participante 8).

Era bom ele acompanhar, pra ver como é ter um filho, ver como a gente se sente (Participante 11).

Ele deveria acompanhar, a gente fica mais segura com uma pessoa da confiança da gente perto (Participante 10).

Seria muito ótimo o pai acompanhar também (Participante 14).

Acho importante para dar mais apoio (Participante 13).

Quero meu marido comigo quando for ter nosso filho (Participante 5).

Todas as mulheres consideraram a possibilidade de serem acompanhadas por seus parceiros bastante positiva, porém esse direito muitas vezes não é garantido, como demonstra os relatos a seguir:

Eles não deixaram meu marido assistir meu parto, fiquei chateada, queria que ele estivesse comigo, nem no outro dia ele pôde ficar comigo, só uma visita bem rápida e pronto (Participante 7).
Quando tive meu primeiro filho, queria que meu marido ficasse comigo, mas não deixaram ele entrar (Participante 9).

O meu também queria participar, mas não deixaram (Participante 1).

O envolvimento do companheiro no processo parturitivo promove pais mais seguros e envolvidos ao evento, a parturiente tem uma evolução mais favorável, sentem-se mais confiantes, reduzindo os índices de intervenções obstétrica, porém como podemos observar nos relatos, o direito da livre escolha de seu acompanhante pela gestante, ainda não é garantido em algumas instituições, fato esse considerado por autores como uma violência obstétrica $^{(15)}$.

\section{Expectativas do apoio paterno no parto e nascimento}

Quanto ao tipo de parto e a presença paterna nesse momento, foi evidenciado que todas as gestantes participantes, desejavam o parto normal com a presença de seu companheiro, fato este que chamou atenção dos pesquisadores. Os relatos selecionados a seguir demonstram essa pretensão:

Eu quero parto normal, já tive um e achei bom, a gente vai logo para casa, meu esposo poderia ajudar (Participante 2).

Prefiro que seja normal mesmo, ele pode me ajudar né? (Participante 4). 
Minha expectativa é ter um parto normal rápido. Me sinto preparada, sonho com meu filho nos braços (Participante 9).

Sobre o parto, seja o que Deus quiser, mas eu prefiro ter normal, ficaria mais segura com o pai dela lá (Participante 3).

Ele queria me ajudar na hora da dor (Participante 6).

Normal é melhor porque a recuperação é mais rápida (Participante 12).

O bom de ter parto normal é que depois que a criança nasce pronto, quero o meu normal mesmo (Participante 8).

Seria muito bom ajudar nosso filho nascer (Participante 11).

Não é tão ruim como as pessoas dizem não, dá pra suportar e se meu esposo ficar é melhor ainda (Participante 13).

Com relação à percepção das gestantes sobre o parto, o vocábulo "dor" apareceu em diversas falas, sendo considerado o principal desafio a ser superado durante o período parturitivo, que desperta sentimento de medo entre as gestantes, principalmente naquelas que estão em sua primeira experiência gestacional, conforme expressa as narrativas:

Eu tenho medo da dor que a gente sente para ter um filho, é muito sofrimento (Participante 1).

Eu tenho um pouco de medo da dor, sei que não precisa ter medo, a gente tem que tirar isso da cabeça (Participante 13).

Quando a gente está grávida, tem pessoas que ficam colocando na cabeça da gente que não vamos conseguir ter um filho normal, porque dói muito (Participante 11).

O medo da dor também apareceu em elocuções relacionadas à cesárea, como podese identificar no relato da participante 6 .

Em relação à cesárea eu não tenho medo na hora, tenho medo é depois, com toda aquela recuperação, também se tiver complicações, a gente vê tanto caso (Participante 6).

Percebeu-se que o vocábulo “dor", teve diferentes configurações entre os dois tipos de partos descritos. No parto normal, o medo foi associado com a dor e ou sofrimento, já na cesariana o medo se estabeleceu mais explicitamente no processo de recuperação e na possibilidade de complicações durante o procedimento.

\section{DISCUSSÃO}

A figura masculina vem passando por diversas mudanças sociais e culturais, deixando de ser apenas um mero mantenedor familiar, para estar junto da mulher durante a gestação e na parturição ${ }^{(1-2,16-17)}$.

A OMS recomenda que a parturiente seja acompanhada por pessoas que confie e se sinta confortável ${ }^{(8)}$. Todas as mulheres 
consideraram a possibilidade de serem acompanhadas por seus parceiros bastante positiva, porém esse direito muitas vezes não é garantido. Um estudo realizado em Goiás mostrou mais de $70 \%$ das parturientes também queriam ser acompanhadas por seu parceiro $^{(18)}$.

Contudo, o apoio e o estímulo à permanência do pai no período parturitivo advindos dos profissionais de saúde não é uma realidade vivenciada pela maioria dos casais brasileiros. Visando maior participação dos companheiros no cenário do nascimento do filho, faz-se necessário que os profissionais atuantes na assistência obstétrica, estejam atentos e dispostos a estimular a participação ativa dos homens no contexto da parturição.

A presença do parceiro pode cooperar para o fortalecimento da mulher, oferecendo apoio, segurança, confiança e conforto à parturiente, contribuindo de maneira expressiva no trabalho de parto e no momento do parto. O companheiro deve ser o primeiro a apoiar à mulher, pois embora em posições diferentes, ambos vivenciam o mesmo fenômeno.

Ressalta-se que neste cenário, o enfermeiro, sobretudo aquele que atua junto à mulher no processo de parturição, apresentase como um profissional importante na luta contra rotinas institucionais e na banalização do cuidado. E, ao abrir mão de preconceitos e rotinas inadequadas, contribui para uma experiência positiva em termos do parto e nascimento. Este profissional tem papel decisivo na luta pela integração do parceiro da mulher no processo parturitivo como parte do cuidado de enfermagem e, consequentemente, como forma de promover a humanização da $\operatorname{assistência~}^{(17,19-20)}$.

Assim, é possível afirmar que a Enfermagem vem contribuindo e participando de forma efetiva para a adesão dos princípios atuais nacionais e internacionais preconizados para atenção humanizada ao parto e nascimento $^{(21)}$.

No presente estudo, todas as mulheres participantes nutriam expectativas de um parto normal. Essa preferência também foi percebida em estudo realizado com 85 gestantes no Sul do Brasil, em que 74,1\% das mulheres manifestaram desejo por essa via de parto, por se tratar de um processo prático e livre de intervenções cirúrgica ${ }^{(22)}$. Este resultado coincide com outra pesquisa, na qual a maioria das mulheres pesquisadas $72,8 \%$ preferiu a via natural, sobretudo para evitar a dor ocasionada pela cirurgia cesariana $^{(24)}$.

Também está de acordo com outra pesquisa, na qual a maioria das gestantes 90,0\% manifestou preferência pela via de parto natural, justificada pela praticidade do procedimento e por medo de sofrimento e dor após o parto cesariano ${ }^{(24)}$. Infelizmente a nítida preferência pelo parto normal das 
gestantes se contrasta com os altos índices de cesáreas observadas atualmente no Brasil.

Um estudo explorou a preferência dos médicos obstetras em relação à via de parto, evidenciando que $63,6 \%$ preferiam realizar cesáreas que acompanhar um parto normal ${ }^{(22)}$. Se por um lado temos a maioria das gestantes e seus parceiros optando pela via de parto normal, por outro, ainda há muitos profissionais que priorizam a intervenção cirúrgica com justificativa de ser um procedimento confortável, seguro tanto para a mãe como para o feto, ter possibilidade de um agendamento prévio ou dar "menos trabalho" para o profissional que acompanha.

O parto natural tem inúmeras vantagens, tanto para a mãe quanto para o bebê, incluindo recuperação mais rápida, ausência de dor no período pós-parto, alta precoce, menor risco de infecção e de hemorragia, conforme mencionaram as Participantes 2, 3, 9 e 12. Por essas razões, de acordo com as recomendações da Organização Mundial da Saúde, as cesarianas devem ser restritas, correspondendo no máximo a $15 \%$ do total de partos e somente ser indicadas nos casos de risco para a mãe ou bebê, constituindo assim, uma alternativa para quando ocorressem complicações durante a gravidez ou parto natural, e não de forma indiscriminada e desnecessária como se vê atualmente $^{(8)}$.

Uma estratégia para reduzir esses índices é a preparação prévia dessas mulheres desde o pré-natal, tornando-as protagonistas do evento, para que possam participar das tomadas de decisões junto com seu parceiro e o profissional que os acompanha. A horizontalidade da assistência com a inclusão de outros profissionais como os enfermeiros obstetras no acompanhamento parturitivo também tem se mostrado benéfico e contribuído para minimizar os índices de intervenções e de procedimentos invasivos desnecessários, por respeitar a fisiologia da mulher na parturição ${ }^{(18,25-26)}$.

Um dos principais desafios em relação a via de parto natural relatado pelas mulheres é a "dor". Essa dor, a que as gestantes se referiram, está relacionada ao trabalho de parto fisiológico, proveniente da dilatação cervical e das contrações uterinas.

No entanto, a sensação de dor é muito subjetiva, sofre influências culturais, psíquicas, emocionais e sociais. Quando uma parturiente se empodera de fato do processo de parturição, essa sensação de dor não se codifica em sofrimento, produz um novo significado, por ser um momento provedor de emoções e alegria pelo encontro real com seu bebê. Vale ressaltar que métodos alternativos efetivos podem contribuir de forma significativa para o alívio dos desconfortos vivenciados durante esse período, sendo farmacológicos ou não, pois ao minimizar a experiência da dor, permitem que a mulher se torne mais participativa e assuma o controle no processo do parto $^{(27-30)}$. 
A insegurança da mulher, ocasionada muitas vezes pela sua desinformação, em relação a dor no parto normal, pode contribuir na escolha por uma cesárea desnecessária. Além do mais, muitas delas demonstram insatisfação com a falta de oportunidade para expressar suas expectativas, preocupações e tirar suas dúvidas com relação ao parto. Nesse sentido, a orientação deve fazer parte da assistência pré-natal ${ }^{(31-32)}$.

\section{CONSIDERAÇÕES FINAIS}

O estudo com as gestantes possibilitou conhecer suas percepções acerca do acompanhamento paterno no trabalho de parto, parto e nascimento. Todas as mulheres consideraram positivo esse envolvimento por acreditar que essa presença confere mais apoio, conforto, segurança, cumplicidade e parceria para ambos. Defendem também que seus companheiros precisam assumir suas responsabilidades paternas inclusive durante o nascimento do bebê.

Faz-se necessário, por parte dos profissionais de saúde, repensar sobre a preparação e o envolvimento do companheiro da gestante durante todo o processo de gestação, parto e nascimento, pois estudos demonstram vários aspectos positivos relacionados a sua participação, contribuindo de forma favorável no período gravídico, consequentemente no processo parturitivo e na relação com o bebê.
Entender a percepção das gestantes acerca da participação paterna no parto e nascimento dos filhos permite conhecer as lacunas da prática na promoção de casais mais seguros e integrados aos eventos que compreendem o ciclo gravídico e puerperal, incluindo o processo parturitivo. A atuação da enfermagem deve focar nas necessidades de cada mulher gestante de forma individualizada, elaborando estratégias que as tornem junto com seu companheiro protagonistas desse momento. Dessa forma, promoverá no homem, o reconhecimento de seus direitos de pai.

Neste sentido, os profissionais de saúde, em especial os enfermeiros, devem buscar estratégias com vista à inserção do pai no cenário do nascimento, de modo a atuarem ativamente neste processo e, com isso, possibilitar os benefícios inerentes à parceira, ao filho e a si próprio. A carência da figura paterna no cenário dos serviços de saúde precisa ser discutida. Faz-se necessária a implementação de ações que resultem nessa mudança cultural.

Como limitação pode-se destacar o tamanho da amostra devido à baixa adesão aos grupos de gestantes, fato este que exigiu algumas adaptações no percurso metodológico desse estudo. 


\section{REFERÊNCIAS}

1 - Carvalho CSF, Carvalho IS, Brito RS, Vitor AF, Lira ALBC. O companheiro como acompanhante no processo de parturição. Rev Rene. 2015 [citado 20maio2021];16(4): 61321. Disponible en: https://www.redalyc.org/articulo.oa?id=32404 $\underline{1519019}$

2 - Draper H, Ives J. Men's involvement in antenatal care and labour: rethinking a medical model. Midwifery. 2013 [cited 2021 fev 22];29(07):723-9. Disponible en: https://doi.org/10.1016/j.midw.2013.02.007

3 - Santos RS, Goncalves TLC. Sentimentos, sensações e emoções dos pais que vivenciaram o nascimento de seus filhos. Cienc. enferm. 2016 [citado 22fevereiro2021]; 22(1):125-33. Disponible en:

https://scielo.conicyt.cl/scielo.php?script=sci arttext\&pid=S071795532016000100011\&lng =es

4 - Ministério da Saúde (BR). Portaria/GM $n^{\circ} 1459$, de 24 de junho de 2011. Que institui no âmbito do sistema único de saúde - SUS, a Rede Cegonha. Brasília, DF: Ministério da Saúde, 2011. Disponible en: http://bvsms.saude.gov.br/bvs/saudelegis/gm/ 2011/prt1459_24_06_2011.html

5 - Ministério da Saúde (BR). Lei $\mathrm{n}^{\circ}$ 11.108, de 07 de abril de 2005. Altera a Lei $n^{\circ} 8.080$, de 19 de setembro de 1990, para garantir as parturientes o direito à presença de acompanhante durante o trabalho de parto, parto e pós-parto imediato, no âmbito do Sistema Único de Saúde. Brasília: Ministério da Saúde; 2005. Disponible en: http://www.planalto.gov.br/ccivil_03/_Ato20 04-2006/2005/Lei/L11108.htm

6 - Ministério da Saúde (BR). Medidas para estímulo ao parto normal na saúde suplementar. Brasília, 2015. Disponible en: http://www.ans.gov.br/index2.php?option=co $\underline{\text { m_legislacao\&view }=\text { legislacao\&task }=\text { TextoL }}$ ei\&format=raw\&id=2892

7 - World Health Organization. Programming for male involvement in reproductive health. Report of the meeting oh WHO Regional Advisers in Reproductive Health WHO/PAHO. Washington DC, USA September 2001 [Internet]. 2002 [cited 2021 jan 15]. Disponible en: http://whqlibdoc.who.int/hq/2002/WHO_FCH _RHR_02.3.pdf

8 - World Health Organization. Assistência ao parto normal: um guia prático. Genebra, 2000. 93 p. Disponible en: http://www.saude.mppr.mp.br/arquivos/File/k it_atencao_perinatal/manuais/assistencia ao_parto_normal_2009.pdf

9 - Palinski JR, Souza SRRK, Silveira JTP, Salim NR, Gualda DMR. Women's perception on the process of coaching labor. On line Braz J Nurs. 2012 [cited 2021 jan 16]; 11(2): 274-88. Disponible en: http://www.objnursing.uff.br/index.php/nursi ng/article/view/3603

10 - Perdomini FRI, Bonilha ALL. A participação do pai como acompanhante da mulher no parto. Texto contexto enferm. 2011[cited 2021 jan 10];20(3): 445$52 . \quad$ Disponible en: http://www.scielo.br/scielo.php?script=sci_art text\&pid=S010407072011000300004\&lg=en

11 - Gil, AC. Métodos e técnicas de pesquisa social. 7. ed. Editora Atlas SA, 2019.

12 - Trad LAB. Grupos focais: conceitos, procedimentos e reflexões baseadas em experiências com o uso da técnica em pesquisas de saúde. Physis 2009 [citado 10janeiro2021];19(3):777-796. Disponible en: http://www.scielo.br/scielo.php?script=sci_art text\&pid=S010373312009000300013\&lng=e $\underline{\mathrm{n}}$

13 - Bardin L. Análise de conteúdo. Lisboa: Edições 70. 2016. 
14 - Ministério da Saúde (BR). Conselho Nacional de Saúde. Resolução $n^{\circ}$ 510/16 sobre pesquisa envolvendo seres humanos. 2016. Diário Oficial da União [periódico na internet], Brasília (DF). 07 abr 2016 [citado 21janeiro2021]. Disponible en: http://bvsms.saude.gov.br/bvs/saudelegis/cns/ 2016/res0510_07_04_2016.html

15 - Carvalho L, Oliveira I, Silva RM, Alves $\mathrm{T}$, Fontenele FM, Carvalho R. Adesão às práticas seguras na atenção ao parto. REAID [Internet]. 29jun.2020 [citado 03maio2021];92(30). Available from: https://revistaenfermagematual.com/index.php /revista/article/view/597

16 - Melo RM, Ângelo BHB, Pontes CM, Brito RS. Conhecimento de homens sobre o trabalho de parto e nascimento. Esc. Anna Nery. 2015 [citado 12fevereiro2021];19(3): 454-459. Disponible en: http://www.scielo.br/scielo.php?script=sci_art text\&pid=S141481452015000300454\&lng=e $\underline{\mathrm{n}}$

17 - Alves MC et al. Support actions undertaken for the woman by companions in public maternity hospitals. Rev. Latino-Am. Enfermagem. 2018 [cited 2021 fev 10];26: e2994. Disponible en: http://www.scielo.br/scielo.php?script=sci_art text\&pid=S010411692018000100309\&lng=e $\underline{\mathrm{n}}$

18 - Mattos DV, et al. Sentimentos vivenciados por parturientes em razão da inserção do acompanhante no processo parturitivo. Revista de enfermagem UFPE 2016 [citado 20fevereiro2021];10(6):4735$4740 . \quad$ Disponible em: http://10.5205/reuol.8200-71830-3-

SM.1006sup201604

19 - Ministério da Saúde (BR). Secretaria de Ciência e Tecnologia. Departamento de Gestão e Incorporação de Tecnologias em Saúde. Diretrizes nacionais de assistência ao parto normal: versão resumida [recurso eletrônico]. Brasília, 2017. Disponible en: http://bvsms.saude.gov.br/bvs/publicacoes/dir etrizes_nacionais_assistencia_parto_normal.p $\underline{\mathrm{df}}$

20 - Ministério da Saúde (BR). Secretaria de Atenção à Saúde. Gravidez, parto e nascimento com saúde, qualidade de vida e bem-estar / Departamento de Ações Programáticas Estratégicas. Área Técnica de Saúde da Mulher. - Brasília: Editora do Ministério da Saúde, 2013. Disponible en: http://bvsms.saude.gov.br/bvs/publicacoes/gra videz_parto_nascimento_saude_qualidade.pdf

21 - Alves T, Coelho A, Sousa M, Cesar N, Silva P, Pacheco L. (2020). Contribuições da Enfermagem Obstétrica para as boas práticas no trabalho de parto e parto vaginal. Enfermagem em Foco, 10(4). doi: https://doi.org/10.21675/2357707X.2019.v10. $\underline{\mathrm{n} 4.2210}$

22 - Leguizamon JT, Steffani JA, Bonamigo EL. Escolha da via de parto: expectativa de gestantes e obstetras. Rev. Bioét. 2014 [cited 2021 fev 10];21(3):509-517. Disponible en: http://www.scielo.br/scielo.php?script=sci_art text\&pid=S198380422013000300015\&lng=e n

23 - Weidle WG, Medeiros CRG, Grave MTQ, Dal BSM. Escolha da via de parto pela mulher: autonomia ou indução?. Cad. saúde colet. 2014 [citado 24fevereiro2021];22(1): 46-53. Disponible en: http://www.scielo.br/scielo.php?script=sci_art text\&pid=S1414462X2014000100046\&lng=e $\underline{\mathrm{n}}$

24 - Silva SPC, Prates RCG, Campelo BQA. Parto normal ou cesariana? Fatores que influenciam na escolha da gestante. Revista de Enfermagem da UFSM 2014, [citado 10janeiro2021];4(1):1-9. Disponible en: https://periodicos.ufsm.br/reufsm/article/view/ $\underline{8861 .}$.

25 - Brito CA et al. Percepções de puérperas sobre a preparação para o parto no pré-natal. Rev Rede. $2015 \quad$ [citado 12fevereiro2021];16(4):470-478. Disponible 
en:

https://www.redalyc.org/articulo.oa?id=32404 $\underline{1519003}$

26 - Ferreira IS, Fernandes AFC, Lô KKR, Melo TP, Gomes AMF, Andrade IS. Percepções de gestantes acerca da atuação dos parceiros nas consultas de pré-natal. Rev Rene. 2016 [citado 16janeiro2021];17(3):318$323 . \quad$ Disponible en: http://www.periodicos.ufc.br/index.php/rene/a rticle/view/3444

27 - Sousa K, Sena A, Cunha K. Tecnologias não farmacológicas e tempo de trabalho de parto e parto: revisão sistemática sem metanálise. REAID [Internet]. 18jan.2021 [citado 17maio2021];95(33):e-21012. Available from: https://revistaenfermagematual.com/index.php /revista/article/view/770

28 - Mascarenhas VH, Lima TR, Silva FMD, Negreiros FS, Santos JDM, Moura MAP et al. Evidências científicas sobre métodos não farmacológicos para alívio a dor do parto. Acta paul. enferm. 2019 [citado 10fevereiro2021];32(3):350-57. Disponible en:

http://www.scielo.br/scielo.php?script=sci_art text\&pid=S010321002019000300350\&lng=e $\underline{\mathrm{n}}$

29 - Possati AB, Prates LA, Cremonese L, Scarton J, Alves CN, Ressel LB. Humanização do parto: significados e percepções de enfermeiras. Esc. Anna Nery 2017 [citado 21fevereiro2021];21(4): e20160366. Disponible en: http://www.scielo.br/scielo.php?script=sci_art text\&pid=S141481452017000400203\&lng=e $\underline{\mathrm{n}}$

30 - Henrique AJ et al. Hidroterapia e bola suíça no trabalho de parto: ensaio clínico randomizado. Acta paul. enferm. 2016 [citado 18fevereiro2021];29(6):686-692. Disponible en:

http://www.scielo.br/scielo.php?script=sci_art text\&pid=S010321002016000600686\&lng=e n\&nrm $=$ iso

https://doi.org/10.31011/reaid-2021-v.95-n.35-art.1116 Rev Enferm Atual In Derme v. 95, n. 35, 2021 e-021117
31 - Gonçalves MF, Teixeira EMB, Silva MAS, Corsi NM, Ferrari RAP, Pelloso SM et al. Pré-natal: preparo para o parto na atenção primária à saúde no sul do Brasil. Rev. Gaúcha $\quad$ Enferm. 2017 [citado 13janeiro2021];38(3): e0063. Disponible en: http://www.scielo.br/scielo.php?script=sci_art text\&pid=S198314472017000300401\&lng=e $\underline{\mathrm{n}}$

32 - Martello NV, Wilhelm LA, Cremonese L, Prates LA, Timm MS, Ressel LB. Práticas de cuidado realizadas pelo companheiro na perspectiva da gestante. Rev. enferm. UFPE 2017 [citado 01março2021]; 4574-4578. Disponible en: https://pesquisa.bvsalud.org/portal/resource/pt /bde-33480

\section{Autor correspondente}

Guilherme Frederico Abdul Nour. Rua Prof. Costa Mendes $\mathrm{N}^{\mathrm{o}}$ 1711, bairro Rodolfo Teófilo, Fortaleza - CE, CEP: 60430-140. Contatos: (88) 9.9258-3452, e-mail: guilhermefrede@yahoo.com.br

Submissão: 2021-05-17

Aprovado: 2021-07-27 